\title{
O processo de adoecer do paciente com câncer em cuidado paliativo
}

RESUMO | Objetivo: Compreender como o paciente oncológico em cuidado paliativo vivencia o processo de adoecimento. Método: O estudo é uma avaliação qualitativa de caráter exploratória descritiva, foi realizado no Centro de Pesquisas Oncológicas, em Florianópolis, de outubro de 2017 a fevereiro de 2018. Participaram 10 pacientes internados na unidade de cuidados paliativos. Foi utilizada a análise de conteúdo de Bardin e constituídas três categorias temáticas. Foram respeitados os preceitos éticos de pesquisa. Resultados: pesquisados tinham mediana de 57 anos, ensino fundamental completo, eram viúvos $(40 \%)$ e casados (30\%). Os pacientes oncológicos precisam ser compreendidos em sua integralidade. Foi evidenciado que as crenças ajudam a enfrentar a doença. Cada indivíduo expressou uma forma diferenciada de enfrentar o câncer. Conclusão: É fundamental a comunicação efetiva com o paciente sobre seu real estado de saúde. Considera-se necessárias pesquisas futuras que abordem a temática tratada neste estudo, afim de melhorar os conhecimentos sobre o tema.

Palavras-chaves: Enfermagem; Neoplasias; Cuidados paliativos.

ABSTRACT | Objective: To understand how the oncology patient in palliative care experiences or becomes ill. Method: The study is a qualitative assessment of the exploratory descriptive character, carried out at the Oncological Research Center, in Florianópolis, from October 2017 to February 2018. Participated 10 patients admitted to palliative care units. A Bardin content analysis was used and three thematic categories were constituted. The ethical precepts of the research were respected. Results: surveyed had a median of 57 years, complete elementary school, were widowed (40\%) and married (30\%). Cancer patients need to be fully understood. It was evidenced as the victims of a disease attack. Each individual expresses a different way to fight cancer. Conclusion: Effective communication with patients about their real health status is essential. Consider the following future research that addresses the theme addressed in this study, to improve knowledge on the topic.

Keywords: Nursing; Neoplasms; Palliative care.

RESUMEN | Objetivo: comprender cómo el paciente de oncología en cuidados paliativos experimenta el proceso de la enfermedad. Metodología: El estudio es una evaluación descriptiva cualitativa y exploratoria, realizada en el Centro de Investigación Oncológica, en Florianópolis, de octubre de 2017 a febrero de 2018. Participaron 10 pacientes ingresados en la unidad de cuidados paliativos. Se utiliza el análisis de contenido de Bardin. Se respetaron los preceptos de la investigación ética. Resultados: los pacientes con cáncer deben entenderse completamente. Se ha demostrado que las criaturas ayudan a enfrentar la enfermedad. Cada individuo expresa una forma diferente de tratar el cáncer. Conclusión: se cree que la comunicación efectiva con el paciente acerca de su estado de salud esencial real. La investigación futura se considera necesaria para abordar el tema abordado en este estudio, con el fin de mejorar el conocimiento sobre el tema.

Palavras claves: Neoplasia. Cuidados paliativos. Muerte y morir.

\section{Josué Jonildo Floriano}

Enfermeiro. Pós-graduando em Enfemagem em Emergência e Terapia Intensiva em Enfermagem - Univerdade do Sul de Santa Catarina - UNISUL. Atua na Policlínica Municipal de Palhoça - UNISUL.

ORCID: 0000-0003-2240-6901

\section{Lorena Melo Schwinden}

Enfermeira. Especialista em Análise de qualidade. Gestora de equipe de produção e Responsável técnica da DMI Diagnóstico médico por Imagem.

ORCID: 0000-0003-3662-0861

\section{Fábila Fernanda dos Passos da Rosa}

Enfermeira. Especialista em Terapia Intensiva. Mestre em Educação e Saúde pelo Departamento de Pós- Graduação em Enfermagem da Universidade Federal de Santa Catarina. Docente na Anhanguera. Docente na Faculdade Censupeg.

ORCID: 0000-0002-4171-9965

\section{Anna Zuffo}

Discente do Curso de Enfermagem. Faculdade União Bandeirante Anhanguera - Campus São José - São José (SC) Brasil. Membro da Liga acadêmica de trauma e Emergência Anhanguera LATEA. Integrante do projeto de pesquisa - Monitoria em Enfermagem.

ORCID: 0000-0003-2919-6994

\section{Barbara Letícia Dudel Mayer}

Enfermeira, Metre em Enfermagem, Doutoranda em Enfermagem pela Universidade Federal de Santa Catarina. Docente do curso de Enfermagem da Faculdade Anhanguera São José/SC. ORCID: 0000-0003-4848-9450

Recebido em: 20/07/2020

Aprovado em: 06/08/2020
INTRODUÇÃO

$\Lambda$ modificação do estilo e qualidade de vida, bem como o estresse e a busca constante por melhorias na carreira profissional está tornando o ser humano susceptivel ao aparecimento de doenças crônicas a ponto de aproxima-lo da morte. Dentre essas patologias, uma das que merecem destaque são as neoplasias por trazerem aspectos de finitude, que ocasionam modificações emocionais e estruturais importantes ${ }^{1}$.

Com base no documento World Cancer Report da International Agency for Research on Cancer (IARC), da Organização Mundial da Saúde (OMS), é esperado que, nas próximas décadas, o impacto do câncer na população cor- 
responda a $80 \%$ dos mais de 20 milhões de casos novos estimados para $2025^{2}$.

As neoplasias podem ser entendidas como uma formação desordenada de um conjunto de células, que invadem outros tecidos e órgãos do corpo além do seu ponto de origem ${ }^{1}$. Trata-se de uma doença crônica e progressiva, gerando dor física, sofrimentos emocionais e psicoespirituais intensos ${ }^{3}$.

Para suportar tal diagnóstico, o paciente com câncer apega-se a espiritualidade e vive a esperança de cura constante, esses são mecanismos de defesa utilizados para burlar a realidade. Outro fator importante é o temor quando projetam a sua ausência permanente no ambiente familiar, provocando profundo sofrimento no indivíduo e naqueles que amam ${ }^{1}$.

O hospital se torna a extenção do seu lar levando o paciente com cancer à separação brusca de tudo o que ama e reconhece como seu, projetando o mesmo a um ambiente solitário e impessoal ${ }^{4}$. O apoio emocional, em especial relacionado à espiritualidade, é de extrema importância, pois ajuda na aceitação e preparo para a morte, sendo esta encarada de maneira menos traumática tanto para o paciente como para seus familiares, proporcionando-lhes uma segurança em relação aos acontecimentos que estarão por vir em sua vida ${ }^{5}$.

O cuidado paliativo é uma filosofia que tem como principio o enfrentamento da morte como algo natural, não adia a morte nem prolonga, mas busca promover um alívio da dor e de outros sintomas, valorizando a vida do paciente, amparando as angústias e os medos, fornecendo suporte para que prossiga sua vida de forma mais ativa. Além disso, o cuidado paliativo engloba o olhar à família e equipe multiprofissional, para que possam passar pelo processo de morte e morrer fortalecidos.

É a assistência que se embasa no respeito, na humanização e no acolhimento, guiado pela comunicação, que é o elemento eficaz no processo de cuidado do paciente terminal e de suma importância no tratamento6. Entretanto, é possível evidenciar obstáculos para o desenvolvimento do cuidado paliativo, seja por falta de entendimento dos trabalhadores envolvidos ou carência de estrutura física ou intelectual das instituições de saúde ${ }^{7}$.

Frente o exposto, esta pesquisa busca compreender como o paciente com câncer em cuidado paliativo vivencia o processo de adoecer, no sentido de responder a seguinte questão norteadora: Como o paciente com câncer em cuidado paliativo vivencia o processo de adoecer?

\section{METODO}

Trata-se de pesquisa qualitativa de caráter exploratória descritiva. Desenvolvida na unidade de cuidado paliativo do Centro de Pesquisas Oncológicas - CEPON, em Florianópolis, Santa Catarina. Este, compreende instituição pública de referência no tratamento oncológico em Santa Catarina. Participaram do estudo 10 pacientes internados na unidade de cuidados paliativos. Foram utilizados como criterios de inclusão: maior de 18 anos, estar ciente do diagnóstico de câncer, consciente, comunicativo, ser indicado pela equipe multiprofissional. Como critérios de exclusão: estar sob efeito de opióide, com algum impedimento de comunicação. A coleta de dados foi realizada de outubro de 2017 a fevereiro de 2018. Os dados coletados foram registrados em um diário de campo, no qual foi descrito as impressões, sentimentos, as experiências vividas por meio da observação e interação durante o processo de cuidar e de morrer do paciente hospitalizado. Além da entrevista, foi desenvolvido também a observação participante com o olhar voltado para a equipe de saúde durante o processo de cuidar, principalmente na abordagem do paciente em fim de vida. As entrevistas com os pacientes foram agendadas previamente conforme possibilidade dos mesmos, e teve duração média de 30 minutos. O instrumento é composto de perguntas abertas e semi-estruturadas, em que os dados registrados deram origem às categorias de análise, com base no referencial teórico de Paterson e Zderad e artigos científicos atualizados. Foi utilizada a análise de conteúdo categorial e temática ${ }^{8}$. A análise de Bardin permitiu definir três categorias temáticas que foram desenvolvidas a partir da saturação dos dados coletados. Para ilustrá-las serão utilizadas falas identificadas por sentimentos e emoções humanas, a fim de preservar a identidade e garantir o sigilo das informações compartilhadas pelos participantes. O estudo obedece aos preceitos éticos de pesquisa conforme resolução, pesquisados que aceitaram participar da pesquisa assinaram Termo de Consentimeno Livre e Esclarecido em duas vias. Projeto aprovado por Comite de ética $\mathrm{n}^{\circ} \mathrm{CAAE}$ : 71247317.0 .0000 .5369$.

\section{RESULTADOS}

Os participantes tinham a mediana de 57 anos, houve a predominância da doença nas idades acima dos 50 anos. Com relação a escolaridade, apenas um dos participantes concluiu o ensino superior, seis não passaram do ensino fundamental, sendo que cinco desses nem chegaram a concluir. O baixo grau de escolaridade pode indicar um aumento na incidência de câncer, o que se destaca nos resultados da pesquisa. Quanto ao estado civil, os dados demonstram que a maior parte dos participantes eram viúvos (40\%), seguidos dos casados (30\%). A seguir são apresentadas as categorias temáticas.

CATEGORIA 1. VIVENCIANDO O PROCESSO DE ADOECER: UM CAMINHO DE INCERTEZAS

Ao encarar o processo de adoecer, vivenciado pelos doentes oncológicos 
sem prognósticos de cura, percebe-se não só efeitos carnais da doença, mas principalmente fenômenos emocionais, mentais e espirituais bastante significativos, já que a doença sensibiliza tanto o paciente quanto sua família nessa nova etapa. Após um maior tempo de tratamento e conhecimento do prognóstico, juntamente as dores e angústias, percebe-se que mais "cansado" o paciente se sente, como sugerem a seguinte fala:

...faz 6 anos. 2010... 2011. Aí eu fiz a cirurgia, fiz radio, fiz "quimio", 5 anos sem nada! Aí veio a lesão no pulmão, mas não é metástase do outro, começou com uma lesãozinha, aí fizemos uma biópsia, deu negativo, mas ela progrediu né? Aí já começamos os tratamentos. Faz um... o ano passado... esse ano... 2 anos! (Entrevistado 1).

Diante desse momento, acontece a formação do vínculo e do envolvimento emocional entre o doente, família e equipe de enfermagem ${ }^{9}$. Questionados acerca do acompanhamento de entes queridos, grande parte dos entrevistados relatou a presença da família e amigos, como percebe-se nas palavras a seguir:

Sim, minha mãe passava os dias comigo e meu pai e minha irmã revezavam durante a noite (Entrevistado 2).

Em relação ao entendimento do processo de adoecimento, os pacientes manifestaram dúvidas quanto a causa da doença. As falas que expressam essa dúvida são claras:

Bá! Esse é um pensamento que eu me pergunto até hoje. Ainda não achei resposta. "Por que eu? ", "Por que comigo? " e "Por que, que eu sinto tanta dor? " (Entrevistado 3).
Por outro lado, observando a fala de Perseverança, este demonstrou ter certo conhecimento e consciência da possível causa da patologia:

Acho que não tem uma explicação certa, foram diversos fatores que levaram a desencadear essa doença no meu corpo (Entrevistado 2).

No que se refere as emoções, foi evidenciado que nessa altura do tratamento os mais diversos tipos de sentimentos podem se expressar, como medos, angústia, tristeza e fracassos, o que mostram os seguintes dizeres:

Confuso, se é o que eu posso responder, se é isso o que vocês queriam escutar, [...] não sei se isso que eu vou falar se está certo, que tem hora que eu não acredito que isso está acontecendo comigo, mas na verdade tá, né? (Entrevistado 5).

Diante disso, observou-se por meio dos questionamentos realizados nos participantes da presente pesquisa essa variedade de sentimentos e dúvidas referentes a doença, evidenciados através das falas, olhares e linguagem corporal, que por vezes demonstrava emoções implícitas. Cada indivíduo expressa uma forma diferenciada de enfrentar a doença, a partir dos relatos foi possível apreender que cada paciente apresentava um momento do estágio do processo de morte e morrer:

Eu estou enfrentando ela. Entreguei a Deus, que Deus, se eu for merecedor que põe uma pessoa em meu caminho que me consiga curar, cure com a mão dele, que ele tem poder me cure se eu for merecedor e eu peço assim, e agradeço, pois não adianta gritar, implorar, isso não adianta, Deus sabe, Deus sabe que nós três estamos aqui conversando (Entrevistado 6).
Dentro desse contexto, observou-se nos dizeres dos entrevistados a procura de algo positivo para explicar a doença, que por vezes era encarada como uma missão de vida, como um dever ou incumbência a ser enfrentada em nome de um Ser Superior, ou ainda como um objetivo maior além do sofrimento ocasionado pelo câncer.

\section{CATEGORIA 2. COMPREENDENDO} O CUIDADO PALIATIVO

Frente a terminalidade humana, o cuidado paliativo se torna essencial, pois busca uma melhor condição de saúde na finitude, atenuando o sofrimento, ansiedade e depressão diante da morte. No questionamento aos entrevistados, sobre a reação ao início dos cuidados paliativos, foi observado que o entendimento do termo "paliativo" não estava bem esclarecido pela maioria dos pacientes, estes entendiam a gravidade da doença, no entanto não compreendiam a aproximação de sua finitude. Essa incompreensão fica perceptível na seguinte fala:

Se disser para ti assim, que eu reagi mal? Não! Mas também foi um choque! Entendesse? Mas assim "óh"! Pelo profissional que é o meu médico, Dr. X, que ele não ficou na sala para falar para mim [...]. Pelo profissional que ele é, ele ter feito isso aí! Estava na sala do lado, ele não veio falar isso pra mim. Não veio lutar junto comigo! Entendesse? Só isso (Entrevistado 1).

Entretanto, alguns pacientes demonstraram conhecimento sobre do que se trata receber o cuidado paliativo:

Fiquei abalado né? Porque a médica disse para mim que não tinha mais solução, só paliativamente. Só podia me dar um... uma qualidade de vida melhor, mas cura não tinha (Entrevistado 3). 
Observou-se, portanto, que a sensibilidade frente as manifestações do paciente, consiste em uma habilidade diferenciada e minuciosa de compreender o imperceptível, o profissional da saúde, sobretudo o enfermeiro, utilizando da comunicação verbal e não verbal, possibilita a prevenção de agravos, alívio da dor e demais sintomas presentes nesse processo de finitude. Visto isso, acredita-se ser fundamental comunicar o paciente sobre seu real estado de saúde, para que este colabore com o tratamento. Diante desse raciocínio, os entrevistados foram indagados sobre os cuidados que estavam recebendo, ficando claro a satisfação e agradecimento de forma unânime, valorizavam a maneira com que a equipe multidisciplinar lidava com suas dores e angústias, assim como a condução dos demais sintomas de maneira humanizada, o que nos fica perceptível nas conversas a seguir:

Eu acho que os cuidados são bons, já estou a quase 10 anos paliativo (Entrevistado 7).

Muito bem, está muito bom os cuidados aqui, que estão tendo comigo, eu sou bem tratada aqui no hospital, sou bem tratada em casa, tenho prioridade no tratamento, tem carinho (Entrevistado 8). "

Na estruturação do cuidado ao paciente sem prognóstico de cura, foi possível compreender que os profissionais alcançam sentimentos de realização, dever cumprido e satisfação ao perceber os resultados do seu trabalho através do reconhecimento exposto pelo paciente e seus familiares.

CATEGORIA 3. A FÉ COMO ALICERCE NO ENFRENTAMENTO DO PROCESSO DE ADOECER

Primeiramente, para falar sobre a fé, é preciso pronunciar a "espiritualidade", esta é mais ampla que a religião, é algo pessoal, se relaciona com os valores, com as crenças interiores, abrange a harmonia e a conexão com as pessoas e consigo mesmo. A espiritualidade dá sentido à vida e independe da religião, propiciando a habilidade de lidar com os mais diversos sentimentos, mobilizando energias positivas e melhoria da qualidade de vida. Acredita-se que a compreensão das crenças, revela uma postura de preocupação do profissional frente aquele que recebe o cuidado. Essa preocupação reflete os princípios bioéticos do respeito à autonomia do paciente, em seguir a crença que julgar melhor, por mais que sejam diferentes e fujam dos padrões gerais ${ }^{10}$. Ao abordar os participantes da pesquisa sobre como suas crenças ajudam a enfrentar a doença, a maior parte das respostas foram positivas, apareceram muitas vezes a crença na existência de um ser superior, em outras, acreditavam ser recompensados no pós-morte, que estão "pagando" algo em vida:

Eu acho que se não fosse os cuidados [...] e a fé, eu não tinha enfrentado, porque foi um caminho bem tortuoso, está sendo ainda né (Entrevistado 7).

É interessante notar como alguns participantes declararam acreditar em Deus, mas sem mencionar uma instituição religiosa, o que caracteriza a espiritualidade. A esperança de cura foi a resposta mais frequente, quando os entrevistados foram questionados sobre o que esperam após todo o caminho percorrido em busca de tratamento. Por outro lado, alguns demonstraram saber que o final de sua vida estava próximo, porém, tinham a esperança de não ter mais sofrimento.

Bom, eu vou começar pelo alto... Eu espero, daqui a chamada de Deus primeiro... Em primeiro lugar. [...]. Então, se ele vai me dar essa passagem, mais leve entende?! [É possível per- ceber uma certa emoção nestas palavras] Que não seja dificultosa para os parentes, para mim, entende? Isso, ai. E agradeço muito, estar aqui até agora, por ele, por Deus, e pros outros né (Entrevistado 9).

É perceptível nas falas a esperança, mesmo que subentendida. $\mathrm{O}$ cuidado humanizado defendido por Paterson e Zderad deixa claro que "estar com" integralmente é de certa forma nutrir esse sentimento tão necessário para que o paciente consiga suportar os seus dias.

Antes para mim era até normal, porque não tinha acontecido nada. Eu saia, me divertia, tudo! Mas agora, eu vi que eu tenho que ter mais um pouquinho de cuidado comigo, com a doença. Porque ela está ali, né? Mas eu não vou deixar ela... ela... ultrapassar eu! Entendesse? Não vou! Só Deus! Enquanto eu tiver vida para lutar, eu vou lutar (Entrevistado 1)!

A vivência do processo de terminalidade, possibilita aos pacientes uma reflexão acerca da vida, que se expressa através da esperança em ter o prolongamento da vida, convivendo com os vínculos afetivos e familiares11. Dessa forma, a fé, a relação com a família e os amigos, demonstraram ser estratégias de enfrentamento que ajudam o enfermo a lidar com os estresses do adoecimento, facilitando o cuidado, e propiciando alívio dos medos e inseguranças presentes no processo.

\section{DISCUSSÃO}

A faixa etária predominante apontada pela literatura é de 60 a mais de 85 anos, visto que com o envelhecimento populacional, as neoplasias se concentram nas idades mais avançadas, não como uma causa de morbimortalidade, 
mas como um elemento crescente na demanda dos serviços hospitalares 12 .

A idade aumenta o tempo da exposição do indivíduo aos fatores de risco presentes no meio ambiente, o que traz como consequência o surgimento de câncer ${ }^{13}$. Devido as dúvidas e angustias em relação a doença, o paciente sofre, necessitando do apoio dos filhos, parentes e amigos, que por vezes possuem um melhor grau de escolaridade, sendo de fundamental importância no tratamento e entendimento da patologia, uma vez que podem ajudar a pessoa com a limpeza da lesão neoplásica, troca de curativos, alimentação e atividades de lazer ${ }^{13}$.

Graças ao apoio social que os pacientes casados recebem, o tratamento tende a ser mais adequado perante uma doença que ameaça a vida, aumentando o grau de resiliência, com melhor enfrentamento $^{12}$.

O câncer não deve ser tratado com uma questão familiar e sim como um problema, pois a família se torna a principal fonte de apoio ${ }^{14}$. É inevitável que os pacientes pensem em um rápido encurtamento da sua expectativa de vida, remetendo-os à ânsia de inteirar-se de informações sobre a doença e como tudo afetará sua vida a partir desse momento ${ }^{15}$.

Dessa forma, durante o longo processo do tratamento o paciente passa a experenciar sofrimentos, acarretando inúmeras limitações, angústias e sentimento de impotência, exigindo do enfermo a busca de sentido para viver nessa nova condição ${ }^{16}$. A família recebe as informações acerca da condição do paciente, quando este se encontra incapaz de se manifestar ${ }^{17}$.

Tais questionamentos nos remetem ao segundo estágio do processo de morte e morrer, a raiva. Este ocorre quando, para o paciente, não é mais possível negar os fatos, substituindo os sentimentos por revolta, inveja e ressentimento. Cada indivíduo interpreta e reage à doença de acordo com seus próprios es- tigmas referentes a sua experiência pessoal, além disso o câncer provoca um extenso impacto não só fisiológico, mas também psicológico e gera sentimentos de ansiedade, angústia, medo, raiva e dúvidas ${ }^{18}$.

O câncer apresenta-se devido a múltiplas causas, estando assim, associado com os costumes, hábitos de vida e herança genética, além de fatores ambientais que predispõem o paciente a determinados cânceres ${ }^{12}$. O paciente acaba sofrendo com as mudanças físicas, afastam-se do lazer, excluindo-se socialmente, o que resulta em sentimento de inutilidade.

Desse modo, surgem diversas reações emocionais, dentre elas medo, tristeza, ansiedade e depressão, tanto pelo momento enfrentado, quanto pela direção que se encaminha ${ }^{19}$. Esses sentimentos podem reduzir a qualidade de vida, diminuir a adesão ao tratamento e mortalidade, pode gerar sintomas somáticos como a perda de apetite e fadiga, que também estão associados ao próprio tratamento ${ }^{20}$.

No processo de adoecimento, a depressão é uma etapa importante para o enfrentamento da doença, este por sua vez, pode também ser chamado de aceitação ${ }^{17}$. A maioria dos pacientes e seus cuidadores não estão preparados para enfrentar o diagnóstico de uma doença potencialmente terminal, nesse momento passam por estágios emocionais característicos, que não ocorrem necessariamente em sequência, podendo se misturar ou serem vividos no mesmo período ${ }^{21}$.

Nas falas citadas, observam-se estágios como a barganha, depressão e aceitação ${ }^{22}$. É possível identificar a barganha, onde o indivíduo busca um adiamento, um prêmio com a intenção de prolongar a vida, portanto, esse estágio atua de forma positiva, pois a fé atinge a função de construir um compromisso com a vida, de conseguir um companheiro na luta conta a doença ${ }^{17}$.

Já nas palavras de "serenidade", ob- serva-se a depressão, nesta fase quando o indivíduo não consegue negar sua doença, começam a surgir novos sintomas e o paciente se torna mais debilitado, sentimentos de grande perda surgem e é difícil esconder a doença de si19. Já a aceitação é uma maneira de desapego às ilusões, o que provoca no paciente uma mudança perceptível, pela disposição que esta passa a ter em relação a patologia, passando a percorrer um caminho de luta e luto ${ }^{17}$.

A comunicação se torna um agente essencial para o cuidado com a saúde, principalmente quando se trata de cuidados paliativos, assim o relacionamento interpessoal positivo com o doente possibilita a compreensão das suas vivências, para que a assistência humanizada seja desenvolvida em sua totalidade ${ }^{23}$.

No contexto da terminalidade, a comunicação faz-se primordial, pois proporciona ao paciente segurança, confiança, transmite esperança e força $^{24}$. O vínculo criado entre a equipe de saúde, paciente e família, através do contato diário constrói uma relação de confiança, indo além dos mecanismos habituais do cuidado, envolvendo também aspectos psicossociais.

Isso é de grande valor para o doente terminal, que se verifica através das falas de grande satisfação durante toda assistência $^{25}$. Quando o profissional se envolve com o cuidado aos pacientes terminais paliativamente, passam a ser vistos em sua totalidade, e a recompensa que estes recebem é o agradecimento, percebido por meio do olhar, do carinho ao estarem do lado deles nessa luta, além de todo conhecimento diante ao valor da vida ${ }^{19}$.

A espiritualidade permite que o assunto da morte possa ser dialogado entre doente e família, de uma maneira que possibilite um maior preparo para a finitude e permite as tomadas de decisões frente esta. Além disso, proporciona momentos entre enfermo e profissional para alívio do sofrimento, 
percepção da naturalidade da morte e a valorização do viver ${ }^{26}$. A interação entre o paciente, a família e o enfermeiro é fundamental para moderar a carga emocional dos envolvidos nesse processo, permite segurança e identificação das necessidades de cuidado no decorrer do tratamento ${ }^{14}$.

\section{CONCLUSÃO}

A elaboração do estudo proporcionou um despertar para o cuidado humanizado sensível voltado não somen- te para as necessidades físicas, mas sim espirituais e emocionais do paciente que adoece com câncer. É notório que o profissional da saúde, sobretudo o enfermeiro, necessita da comunicação verbal e não verbal, da sensibilidade frente as manifestações do paciente, que consiste em uma habilidade diferenciada e minuciosa de compreender o imperceptível. É fundamental a comunicação efetiva com o paciente sobre seu real estado de saúde, para que este vivencie o processo de forma mais amena. A fé, a relação de afeto com a família e os amigos, demonstraram ser estratégias de enfrentamento que ajudam o enfermo a lidar com os estresses do adoecimento, facilitando o cuidado, e propiciando alívio dos medos e inseguranças presentes no processo de adoecimento. Por fim, reitera-se a necessidade da permanente retirada do véu obscuro que recai não somente sobre a temática do processo de morte e morrer, bem como ao paciente em sua finitudade, ambos merecem ser tratados com respeito e sensibilidade.

\section{Referências}

1. Ferreira VS, Raminelli 0.0 olhar do paciente oncológico em relação a sua terminalidade: ponto de vista psicológico. Rev SBPH [online] 2012 [citado em 04 mai 2017]. 15: 101-113. Disponível em: http://pepsic.bvsalud.org/ scielo.php?script=sci_arttext\&pid=S1516-08582012000100007

2. BRASIL. Instituto Nacional do Câncer José Alencar Gomes da Silva - Inca. Ministério da Saúde (Org.). Incidência de Câncer no Brasil. 2016 [citado em 06 mai 2017].

3. Menegócio AM, Rodrigues L, Teixeira GL. Enfermagem Oncologia: Relação de Afetividade ou Meramente Técnica? Ensaios Cienc., Cienc. Biol. Agrar. Saúde. 2015 [citado em 10 mai 2017] 19: 118-123.

4. Aquino TAA, et al. Falando de morte e da finitude no ambiente escolar: um estudo à luz do sentido da vida. Psicol. cienc. prof. 2014. [citado em 15 mai 2017] 34: 302-317.

5. Santos CO, et al. A influência do apoio emocional no enfrentamento da terminalidade do paciente oncológico. Cadernos de Graduação: Ciências biológicas e da saúde. 2014 [citado 04 mai 2017] 2: 131-139.

6 . Fernandes MA, et al. Percepção dos enfermeiros sobre o significado dos cuidados paliativos em pacientes com câncer terminal. Ciênc. saúde coletiva. 2013 [citado em 6 mai 2017] 18: 2589-2596.

7. Gonçalves NGC, et al. Paciente que Requer Cuidados Paliativos: Percepção de Enfermeiras. In: Anais do Congresso Internacional de Humanidades \& Humanização em Saúde [= Blucher Medical Proceedings, num.2, vol.1]. São Paulo: Editora Blucher, 2014. ISSN 2357-7282. DOI 10.5151/medpro-cihhs-10666

8. Bardin L. Análise de conteúdo. São Paulo: Edições 70, 2011.

9. Almeida CSL, Sales CA, Marcon SS. 0 existir da enfermagem cuidando na terminalidade da vida: um estudo fenomenológico. Revista da Escola de Enfermagem da Usp. 2014 [citado em 20 mai 2017] 48: 34-40.

10. Salles AA. Bioética e processos de religiosidade entre os pacientes com doenças terminais no Brasil. Revista Bioética. 2014 [citado em 17 fev 2017] 22: $397-406$

11. Benites AC, Neme CMB, Santos MA. Significados da espiritualidade para pacientes com câncer em cuidados paliativos. Estudos de Psicologia (campinas). 2017 [citado em 22 mai 2017] 34: 269-279.

12. Matodo LML, Oliveira LEC, Oliveira KKD. Perfil Sociodemografico dos Portadores de Neoplasias nos Serviços de Referência do Rio Grande do Norte. C\&d: Revista Eletrônica da Fainor. 2016 [citado em 17 mai 2017] 1: 235-247.

13. Nogueira WP, et al. Perfil sociodemográfico, clínico e terapêutico de pacientes com feridas neoplásicas. Rev Enferm Ufpe On Line. 2017 [citado em 19 fev 2017] 11: 3039-3049.

14. Leite MAC, Nogueira DA, Terra FS. Social and clinical aspects of oncological patients of a chemotherapy service. Revista da Rede de Enfermagem do Nordeste. 2015 [citado em 16 mai 2017] 16: 38-45.

15. Delevatti VF, et al. Expectativa de vida e perspectiva de futuro em pacientes oncológicos: Revisão sistemática. Revista Psicologia em Pesquisa. 2018 [citado em 15 fev 2017] 12: 15-22

16. Reis CGC, Farias CP, Quintana AM. O Vazio de Sentido: Suporte da Religiosidade para Pacientes com Câncer Avançado. Psicologia: Ciência e Profissão. 2017 [citado em 14 mai 2017] 37: 106-118.

17. Beck AHU. Psico-oncologia: a atuação do psicológo no tratamento de pacientes com câncer. 2017. TCC (Graduação) - Curso de Psicologia, UNIJUI - Universidade Reginal Noroeste do Estado do Rio Grande do Sul, ljuí - RS. 18. Costa JM, et al. Repercussões biopsicossociais do diagnóstico de câncer colorretal para pacientes oncológicos. Rev. SBPH. 2016 [citado em 20 mai 2017] 19: 5-23.

19. Tomaszewski AS. Manifestações e necessidades referentes ao processo de morte e morrer: perspectiva da pessoa com câncer. Revista de Pesquisa: Cuidado é Fundamental Online. 2017 [citado em 13 mai 2017] 9: 705-716. 20. Castro EK, et al. Percepção da doença, indicadores de ansiedade e depressão em mulheres com câncer. Psicologia, Saúde \& Doença. 2015 [citado em 6 mai 2017] 16: 359-372.

21. Paiva FCL, Almeida JJJ, Damásio AC. Ética em cuidados paliativos: concepções sobre o fim da vida. Revista Bioética. 2014 [citado em 7 mai 2017] 22: $550-560$

22. Kübler-ross E. Sobre a Morte e o Morrer: o que os pacientes terminais têm para ensinar a médicos, enfermeiras, religiosos e aos seus próprios parentes. 8. ed. São Paulo: Martins Fontes, 1998.

23. Andrade CG, et al. Cuidados paliativos e comunicação: estudo com profissionais de saúde do serviço de atenção domiciliar Palliative care and communication. Revista de Pesquisa: Cuidado é Fundamental Online. 2017 [citado em 10 fev 2017] 9: 215-221.

24. Brito FM, et al. Fabiana Medeiros de et al. Comunicação na iminência da morte:: percepções e estratégia adotada para humanizar o cuidar em enfermagem. Escola Anna Nery - Revista de Enfermagem. 2014 [citado em 4 mai 2017] 18: 317-322.

25. Oliveira PM, et al. Visão do familiar cuidador sobre o processo de morte e morrer no domicílio. Revista Baiana de Enfermagem. 2016 [citado em 18 mai 2017] 30: 1-11.

26. Arrieira ICO, et al. 0 sentido da espiritualidade na transitoriedade da vida. Escola Anna Nery - Revista de Enfermagem. 2017 [citado em 20 fev 2017] 21: 1-6.

27. Costa JM, et al. Repercussões biopsicossociais do diagnóstico de câncer colorretal para pacientes oncológicos. Rev. SBPH. 2016. [citado em 15 mai 2017] 19: 5-23. 